\title{
MOBILE ASSISTED THIRD SPACE (MATS) - WHAT IS THE POTENTIAL FOR M-LEARNING?
}

\author{
Rebecca Kelly \\ University of Hull, Cottingham Rd, Hull HU6 7RX, United Kingdom
}

\begin{abstract}
This paper outlines the use of Third Space theory to support teaching and learning in the context of educational technologies such as m-learning. This research forms part of a wider project which seeks to better understand the potential of mobile learning and develop a framework for mobile assisted third spaces (MATS). The literature highlights several features of Third Space learning that can be clearly allied to the pedagogic principles outlined in m-learning pedagogy such as the iPAC Framework. The symbiotic nature of Third Space theory and mobile pedagogy is discussed and the potential of MATS to support mobile learning practices are explored.
\end{abstract}

\section{KEYWORDS}

Mobile Learning, Mobile Pedagogies, Mobile Pedagogical Framework (MPF), Third Space, Mobile Assisted Third Spaces (MATS)

\section{INTRODUCTION}

Mobile learning (m-learning) is rapidly establishing itself as a contemporary pedagogy increasing opportunities for innovation in a variety of educational contexts and practices (Burden \& Kearney, 2017). Defined as pedagogy facilitated by portable devices which are ubiquitous, pervasive and offering a diverse range of capabilities (Kearney et al, 2015), m-Learning is situated as learning that untethers users from traditional concepts of time and space (Schuck \& Maher, 2018). M-Learning has been criticized as an under theorized field of research, lacking in conceptual models and frameworks (Koole et al, 2018). Initial attempts to explore how Third Space theory informs the practice of m-Learning and may offer the potential for the development of the frameworks required by the field (Schuck et al, 2017). Third Space Theory's potential for m-learning is a largely under-researched and under-theorised domain of m-learning. This conceptual paper explores how this space might be constituted and is part of a wider study that seeks to develop a theoretical framework for thinking about Mobile Assisted Third Spaces (MATS).

\section{BACKGROUND LITERATURE}

\subsection{What is Third Space}

The concepts of space and place were explored extensively in the latter part of the twentieth century, particularly through the in the works of Soja (1996), Oldenburg (1989) and Bhabha (1994). Third Space theory has since sought to elicit deeper epistemological and ontological understandings in a wide range of disciplines, including education and the broader field of pedagogy. This development in spatial thinking has been used to formulate fresh ideas around the interplay of physical and virtual existences afforded through new technologies (see Lapp et al \& 2014; EVolvi, 2017). Scholars have suggested that space should no longer be viewed as a container of individuals and activity, but rather as a process through which social relations and identities are produced and reproduced (Soja, 1996). The inauguration of Third Space concepts into the field of educational technology has built pace over the last decade (See Aaen \& Dalsgaard \& 2016; Lapp et al, 2014) and has more recently been linked with m-Learning practices (Schuck et al, 2017). 
The study of Third Space theory acknowledges the role of physical location in defining space but also prioritizes the social dimensions that are integral to it (Bhabha, 1994; Soja, 1996; Oldenburg, 1989). These authors stress the importance of human interaction with both sentient and non-sentient elements in defining space. For example, Soja (1996) describes space as a mutually constituted construction between the physical and the social. He argues that physical elements can shape the social interactions within them but also this is a reciprocal relationship and social activities can also shape the physical space around it. Thus spatial thinking moves away from the notion of space as a container of activity or existence towards thinking of space as a process, born from the interplay of interactions and intersections within it (Soja, 1996). Similarly Bhabha's (1994) interpretation of Third Space discards thinking of spatial dimensions as being homogenous or contained, emphasising the cultural dimensions of space. He argues entities of space or time are never unitary and therefore manifestations of culture and discourse must exist between referential systems and beyond cultural borders. A further iteration of Third Space is offered by Oldenburg's 'The Great Good Place' (1989) in which he argues the importance of informal social spaces that bridge the first and second spaces of home and work. Third Places are neutral and inclusive, they facilitate social interactions in which knowledge is shared and new understandings are formed and are therefore crucial for community and society. These aspects of space have been increasingly applied to educational practices (See Gutierrez, 2008 \& Flessner, 2014) and their emphasis on hybridity, rejection of binaries and time/space fluidity has been hailed as fundamentally important m-Learning characteristics (Schuck et al, 2017).

\section{2 iPAC Theory and Third Space}

The iPAC framework captures what its authors refer to as the signature pedagogies of m-learning (Kearney et al, 2012), (see Fig. 1 below). These include the constructs of Personalisation, Authenticity and Collaboration, along with each of their sub-constructs. At the heart of the iPAC framework are the concepts of time and space, which point heavily towards the concept of Third Space.

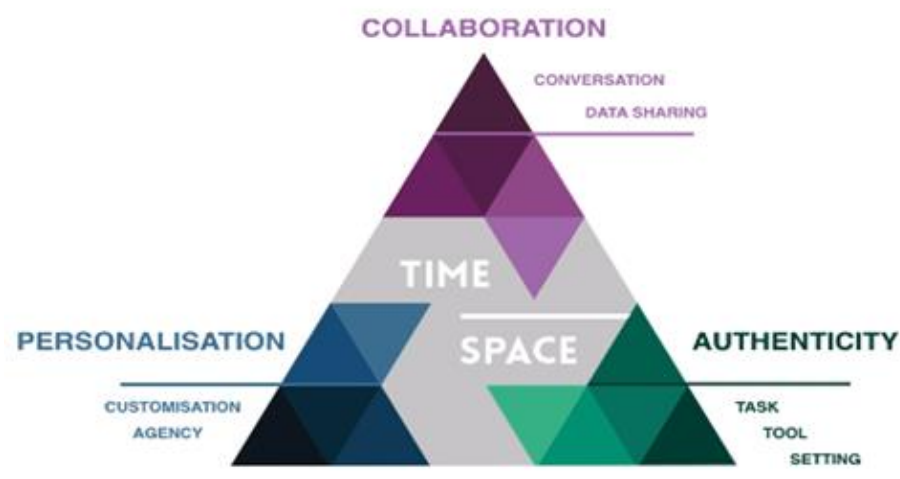

Figure1. iPac Framework, (Burden \& Kearney 2017)

Drawing upon sociocultural perspectives (Burden \& Kearney, 2017) the iPAC framework is analogous with Third Space concepts in several ways. Firstly, the central location of time/space as the epicentre of this framework emphasises the critical influence of context. The framework promotes the importance of innovative uses of temporal and spatial dimensions of learning as crucial to m-learning practice. Secondly, the inclusion of personalisation takes advantage of how learning is experienced individually; learners have an increased agency over how, when and where their learning can occur. Thirdly, Authentic aspects of $\mathrm{m}$-Learning allow learning to happen in realistic contexts making it more transferable between the classroom space and real life spaces. Finally, the collaboration construct privileges the importance of hybrid discourses, interactions between diverse individuals and environments, which is emphasized as a key feature of m-Learning. All the features of m-learning described are apparent in third space pedagogy indicating their synergetic potential, this is explored in detail through this research. 


\subsection{Mobile Assisted Third Spaces (MATS)}

The mutual constitution of m-Learning practices and Third Space is evident. There is a synergetic relationship between Third Space theory, mobile pedagogy and wider socio cultural pedagogies which is the central topic of this research. An initial review of the literature and several small scale pilot studies have generated an anterior framework for considering Mobile Assisted Third Spaces (MATS) in educational contexts (see-Figure 2).

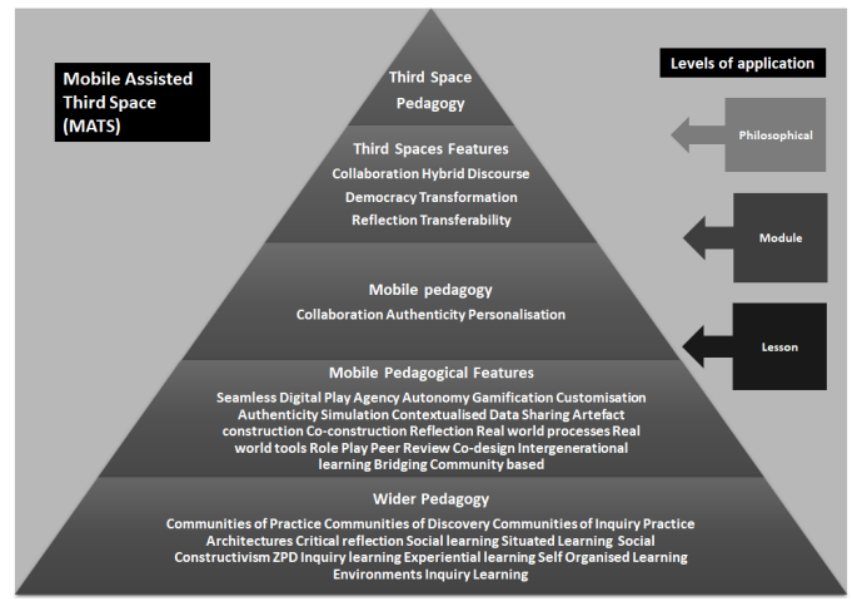

Figure 2. Mobile Assisted Third Spaces (MATS) diagram

The literature highlights a tiered application of Third Space theory as a teaching method. The application of Third Space concepts at the macro level identified a philosophical shift towards Third Space concepts (Flessner, 2014), at a meso level application was identified at the module/syllabus level (Idrus, 2015) and at the micro level application was within a lesson plan or specific activity (Aaen \& Dalsgaard, 2016). It also demonstrates the existence of a hierarchical relationship between sociocultural pedagogy, mobile pedagogy and Third Space pedagogy. These facets of MATS have informed the development of this anterior framework. A brief discussion of the synergy between these pedagogical facets is offered during the next section.

\section{INITIAL EVIDENCE FOR EDUCATION MATS FRAMEWORK}

Ongoing case study research and review of literature in this field highlights several recurring features of Third Space theory for learning: Collaboration, Reflection, Democracy, Transferability, Hybrid discourse and Transformation. Through initial pilot studies analysing m-learning activities specifically using the iPAC framework, and evidence from wider research in m-learning practices the symbiotic nature of the two concepts is evident.

Collaboration allows for learning through social construction and corresponding theories such as Communities of Practice (Lave \& Wenger, 1991) are therefore present in both Third Space learning and m-learning research. Aaen \& Dalsgaard (2016) report findings of student led Facebook groups as a Third Space of school life, indicating a defined community structure through which a shared practice supports and enriches their experiences of school life; this demonstrates the synergetic relationship between these pedagogical aspects. Charitonos et al (2012) highlight how m-Learning practices extend the social spaces in which students/teachers can interact and therefore make learning more ubiquitous. Collaboration necessitates the interaction of two or more discourses, this interaction is used to create a new hybrid discourse which is built from new knowledge/ new understandings generating a hybrid language between collaborators. In order to operationalize the concept of Third Space, Kirkland (2010) calls for a pedagogical Third Space in teaching that synthesizes traditional school literacies with students' lived literacies. The ability for m-Learning to 
facilitate this is evident in Hwang et al (2011) where students co-construct concept maps in which they share and modify their ideas and visualise their knowledge representations.

Almost all of the studies using Third Space for learning explicate their adaptation of a Third Space as a reflective space. Reflection is explored as a key activity in Third Space learning for immigrant education (Dryness \& Hurstig, 2016). Reflection around professional roles/ personal identities, cultural identities and the structure of society is widely purported as necessary within Third Spaces. The capability of m-Learning to enhance reflective practice is evident in Leinonen et al's (2016) evaluation of apps which showed increased engagement in reflective practice as different modes of participation were synchronously available.

Not surprisingly with the extensive use of collaboration and a reliance on the amalgamation of difference into hybrid discourses, Third Spaces are described as inherently democratic places. The work of Freire (1970), is used to explore the potential of Third Space concepts for greater social justice in education (Idrus, 2015). The opportunities afforded by m-Learning to promote the skills required to engage with others and contribute to the community is evident in Barak \& Ziv's (2013) study of students designing interactive, location based artefacts. Many studies recognise the potential of Third Space to support transformational outcomes. Whether this be at a deep level of identity formation (Idrus, 2015) or increasing ability in specific content areas (Flessner, 2014). The transformational potential of m-Learning is made clear in Mintz's (2013) research where mobile technology is used to support behavioural and social development of students with ASD.

The ability of Third Space concepts to bridge the academic and non- academic world is also cited as a crucial feature amongst the articles reviewed. Studies such as Idrus (2015) provide strong examples as they utilise Third Space concepts to actively increase the relevancy and transferability of learning to wider contexts outside of the classroom. M-Learning's capacity to make learning more transferable is clear in Toh et al's (2017) study where students were able to traverse multiple contexts and interact with diverse resources to bridge science learning with the scientific concepts manifest in their everyday lives.

The similarities between m-Learning practices and Third Space learning are clear. Initial case study research in this area highlights evidence of MATS and their potential to support an innovative and even transformational approach to 21st Century learning. MATS offer opportunities to disrupt traditional teaching and learning practices and offer a more current and relevant pedagogy for the 21st Century. The development of MATS answers calls from the m-Learning community for increased theoretical frameworks in this field (Koole et al, 2018) and has the capability to support an unconventional revision of traditional time/space concepts which would initiate the changes in the roles, practices, curriculum and timetable required to fully exploit the opportunities of m-Learning (Schuck \& Maher, 2018).

\section{CONCLUSION}

The symbiotic existence of m-Learning pedagogy and Third Space learning practices is evident. There is clear potential for mobile assisted Third Spaces (MATS) to support the development of contemporary educational praxis and offer an innovative framework for 21st Century learning. The future focus of this research is to empirically explore the affordances of MATS and refine a framework to support m-Learning pedagogy; these findings will be presented as part of this research paper presentation.

\section{REFERENCES}

Aaen, J \& Dalsgaard, C., (2016). Student Facebook groups as a third space: between social life and schoolwork. Learning, Media and Technology, Vol 41, No.1, pp. 160-186.

Barak, M. \& Ziv, S., (2013). Wandering: A Web-based platform for the creation of location-based interactive learning objects. Computers and Education, Vol 62, No 1, pp. $159-170$.

Bhabha, H., (1994). The Location of Culture, Routledge, London.

Burden, K \& Kearney, M., (2017). Investigating and critiquing teacher educators mobile learning practices, Interactive technology and smart education, Vol 14, No. 2, pp. 110-125.

Charitonos, K., et al (2012). Museum learning via social and mobile technologies: (How) can online interactions enhance the visitor experience?, British Journal of Educational Technology, Vol.43, No. 5, pp. 802-819. 
Dyrness, A \& Hurtig, J., (2016) Migrant Third Space Pedagogies: Educative Practices of Becoming and Belonging, Diaspora, Indigenous, and Minority Education, Vol. 10, No. 4, pp. 185-188.

EVolvi, G., (2017) Hybrid Muslim identities in digital space: The Italian blog Yalla, Social Compass. Vol 64, No. 2, pp. 220-232.

Flessner, R., (2014) Revisiting Reflection: Utilizing Third Spaces in Teacher Education, The Educational Forum, Vol 78, No. 3, pp. 231-247.

Freire, P., (1970), Pedagogy of the oppressed, continuum, New York.

Gutierrez, K. D., (2008). Developing a Sociocritical Literacy in the Third Space, Reading Research Quarterly, Vol. 43, No. 2, pp. 148-164.

Hwang, G.J., et al (2011). An interactive concept map approach to supporting mobile learning activities for natural science courses, Computers \& Education, Vol 57, pp. 2272-2280.

Idrus, F., (2015). Examining Classroom Transformational Spaces Using the Third Space Theory in Developing Students' Sense of Shared Identity, Theory and Practice in Language Studies, Vol. 5, No. 1, pp. 28-37.

Kearney, M., et al, (2012). Viewing mobile learning from a pedagogical perspective, Research in Learning Technology, Vol. 20, No. 1, pp. 17.

Kearney, M., et al, (2015). Investigating teachers' adoption of signature mobile pedagogies, Computers \& Education, Vol. 80, No.1, pp. 48-57.

Koole, M., et al, (2018). A Comparison of the uptake of two research models in mobile learning: The FRAME Model and the 3-Level Evaluation Framework, Education Sciences, Vol 8, pp. 114.

Kirkland, D. E., (2010). Teaching English in a Sea of Change: Linguistic Pluralism and the New English Education English Education, Vol. 42, No. 3, pp. 293-306.

Lave, J \& Wenger, E (1991). Situated Learning: Legitimate Peripheral Participation, Cambridge University Press, Cambridge.

Lapp, D. et al, (2014). Blended Learning as a third space, Voices from the Middle, Volume 22 Number 2, pp. 7-9.

Leinonen, T. et al, (2016) Mobile apps for reflection in learning: A design research in K-12 education, British Journal of Educational technology, Vol, 47 No 1, pp. 184-202.

Mintz, J., (2013). Can smartphones support inclusion for autism in mainstream?, Journal of Assistive Technologies, Vol. 7, No. 4, pp. 235-242.

Oldenburg, R., (1989). The Great Good Place, Da Capo Press, Cambridge, USA.

Schuck, S. \& Maher, D. (2018). Creating Opportunities for Untethered learning, Technology, Pedagogy and Education. Online.

Schuck, S. et al, (2017). Exploring Mobile Learning in the Third Space, Technology, Pedagogy and Education, Vol, 26, No. 22, pp. 121-137.

Soja, E (1996), Third Space, journeys to Los Angeles and other real and imagined places, Blackwell, Oxford.

Toh, Y., et al (2017). Transformation of Participation and Learning: Three Case Studies of Young Learners Harnessing Mobile Technologies for Seamless Science Learning. Asia-Pacific Education Researcher, Vol 26, No. 5, pp. 305-316. 